\title{
La política del tinte en la España del siglo XVIII
}

\author{
Pere Molas Ribalta *
}

El proceso del tinte tenía un papel esencial en la industria textil del

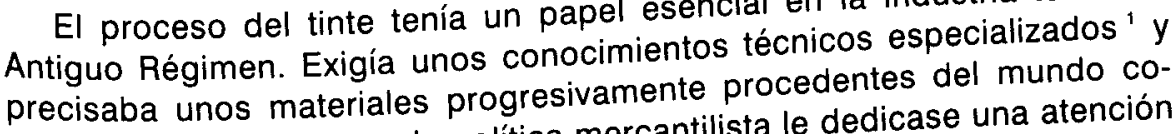
lonial. No es extraño que la política mercantilista le dedicase una atención particular, partiendo de la anterior legislación corporativa o municipal. Colbert hizo elaborar una detallada instrucción en 12 partes y 317 capítulos: la «Instruction generale pour la teinture des laines" de 1671.

\section{LA JUNTA DE COMERCIO Y EL TINTE}

En España el reformismo económico existente en torno a 1680 también mostró interés por el tinte. Eugenio de Larruga, el historiador oficial de la Junta de Comercio, creada en 1679, afirmaba cien años después que, para paliar la defectuosa situación de la industria del tinte en España, la institución ofreció premios a los que descubriesen algún «secreto para tinturaw $^{2}$.

El abogado catalán Narciso Feliu de la Penya, hombre vinculado a la Junta de Comercio e impulsor de iniciativas de renovación textil, recogió datos de procedimientos técnicos utilizados en Francia, Inglaterra y Países Bajos. En 1687 había hecho una redacción catalana, y una traducción castellana para la Junta, a partir de una obra del siglo XVI: «Breu modo

* Universidad de Barcelona.

Sobre el valor de los conocimientos técnicos de

Deyon, en LEÓN, Pierre, Histoire econom politicas y económicas sobre los frutos y fábricas de España, tomo III, pág. 133. 
de donar las tinturas a totas robas de llana, teles i fils» (1578). En 1691 publicó el opúsculo titulado "Ramallet de tinturas» ${ }^{3}$.

Feliu había financiado la estancia en Francia del tintorero de lana de Barcelona, Jacinto Cantarell, para que mejorase sus conocimientos, en especial en el teñido de las medias. Parece que Cantarell destacó en el tinte de escarlata. Uno de sus discípulos fue llamado en 1692 a Madrid por la Junta de Comercio, para que difundiese la citada especialidad. La iniciativa tuvo éxito desde el punto de vista técnico, pero no en el económico, puesto que no se consiguió interesar ni a mercaderes ni tintoreros de la capital ${ }^{4}$.

Finalizada la guerra de Sucesión se reemprendieron los esfuerzos para mejorar la calidad del tinte en España. Los diputados de la industria lanera de Segovia solicitaron en 1720 el establecimiento de un maestro de tinte ${ }^{5}$. En la nueva fábrica de paños de Guadalajara se atendió también a la reforma del tinte. Los esfuerzos más continuados se hicieron en Madrid, con la llegada en 1718 de los extranjeros Turmenier y Pedro Ollier, dos iniciativas sin demasiado éxito. El segundo pretendía la concesión del título de Inspector general de manufacturas y tintes de España ${ }^{6}$. En la corte se había creado ya el cargo de visitador de fábricas, cuyas funciones ejercía a fines de los años veinte Francisco Antonio Tejada. El establecimiento de un inspector general de tintes se llevó a efecto en 1734 en la persona de Manuel de Robles, tintorero del rey y veedor del arte 0 gremio de tintoreros de Madrid.

\section{EL VISITADOR ROBLES}

Robles era persona experimentada en el oficio. En 1727 él y su colega Juan Sedeño acompañaron al visitador Tejada en una inspección de muestras de tinte de la fábrica de Guadalajara. En 1732 solicitó se le nombrara director general de tintes, tanto de los establecimientos estatales como de los privados. En su argumentación exponía la falta de buenos tintoreros y los abusos que se producian en cuanto a la calidad de los colores. Dos años más tarde, el 8 de octubre de 1734, una real cédula le nombraba "director y visitador de tintes de estos reinos" ${ }^{7}$. Estaba obligado a realizar

3 Molas, Pere, Comerç i estructura social a Catalunya i València als segles XVII i XVIII. Barcelona 1977, págs. 103-107.

4 Molas, págs. 106-107. Larruga, III, 133. Archivo General de Simancas. Consejo Supremo de Hacienda. Libro 244, fol. 34.

5 LeÓn Tello, Pilar, Un siglo de Fomento español. Madrid 1980, pág. 333.

- Larruga, Memorias, III, págs. 136-140.

7 Ibidem, págs. 143-146. AGS.CSH. Libro 213, fol. 24. Libro 242, fol. 26. 
una "visita" o inspección de los tintes y a formar una ordenanza general técnica. La formación y la difusión técnicas eran parte importante de la política del tinte. Robles se había comprometido a dar a luz tratados sobre los "secretos" que tenía observados. En la misma real cédula se le mandaba escribir

"Un tratado completo, general y absoluto del arte de tintorero, sus materiales y modo de beneficiarlos".

Larruga comentó que el visitador Robles cumplió algunos de los puntos de su cédula de nombramiento y que trabajó bastante para poner la industria del tinte en buen estado, en especial en los tejidos de seda. Realizó visitas de inspección a los tintoreros de Segovia y de Toledo. En el primer caso constató el carácter tradicional del proceso técnico empleado, el «antiguo y tosco adquirido de sus antecesores". También observó que una adecuada formación técnica requería tiempo y que no se podía obtener una mejora radical desde el comienzo ${ }^{8}$. En 1747 Robles pasó a los pueblos de la provincia de Valladolid donde se cultivaba el colorante vegetal llamado rubia y granza, para vigilar el cumplimiento de la nueva legislación sobre el tema, que acababa de promulgar la Junta general de comercio.

Robles tardó 23 años en redactar el tratado técnico que se le había encomendado. Se publicó en 1757 en forma de ordenanza de tintes. En el prólogo de la misma, la Junta de comercio manifestaba que no se fijaban dosis precisas de los ingredientes, porque una reglamentación estricta hubiera significado

“Impedir las utilidades y progresos de las artes, poniendo límites muy estrechos a los observadores de la naturaleza».

Las ordenanzas exponían el tiempo de duración del aprendizaje: seis años para los tejidos finos y cinco para los bastos. La oficialía era respectivamente de dos y uno. Las ordenanzas eran especialmente detalladas en el conocimiento de los cuatro colores o "tintas" principales, sus ingredientes, variantes y combinaciones. Los cuatro colores eran, por su orden: azul, rojo, amarillo y negro. Del azul derivaban los verdes y morados. El negro era necesario para "sombrear y oscurecer" numerosos colores. En cuanto ingredientes, se citaban el pastel y el añil para el azul;

B Lafruga, Memorias, tomo IX, pág. 228 y XIII, pág. 230. 
para el rojo, la cochinilla, la agalla, el brasil y la «kehermes» o grana silvestre de las coscollas, así como la rubia. Para el amarillo se podía utilizar la gualda, muy abundante en España, «así silvestre, como en cultivo». Para el negro se usaba el zumaque y la agalla ${ }^{9}$.

Las cuatro tintas principales se recogían en las ordenanzas de los tintoreros de seda de Valencia de 1763, pero en 1771 una circular de la Junta de Comercio denunciaba que muchos municipios habían concedido títulos de tintorero "en contravención a las ordenanzas», y prescribía el fortalecimiento de las inspecciones ${ }^{10}$.

Manuel de Robles se mantuvo al frente de la inspección de tintes durante 32 años. Su sucesión fue esperada y solicitada por diversos maestros tintoreros de alguna fama. En 1756, Juan de Mansilla Aliseda, que se titulaba «maestro tintorero y fabricante de rubia» pedía el ejercicio del cargo durante las ausencias y enfermedades de su titular ${ }^{11}$. En octubre de 1763 solicitó la plaza Cristóbal Sedeño, maestro tintorero de sedas y paños de Madrid, originario de una familia de tintoreros toledanos. Un paisano y colega suyo confirmaba que Cristóbal Sedeño había sido un excelente maestro. En 1773 la Junta de Comercio le envió a Valencia para enseñar el uso de las tinas "para los buenos y verdaderos azules y verdes» 12 .

El cargo no fue para Sedeño ni para Mansilla, sino para el catalán Juan Pablo Canals, el cual también había solicitado en 1763 la futura sucesión de Robles. Mansilla, que había sido sobreveedor del arte de tintoreros de Madrid, pidió que se le nombrara teniente del director general. La Junta de Comercio aprobó la pretensión «para las visitas extraordinarias y a costa de Canals", pero el rey rechazó el nombramiento, indicando que en tales casos la Junta se podía valer «del maestro más perito en el arte", haciendo pagar las costas a Canals, cuando este no pudiera desempeñar sus funciones ${ }^{13}$.

En 1778 entró en la rueda de aspirantes José Benedicto, un piamontés que era maestro tintorero en la real fábrica de sedas de Talavera. Ya en

- Archivo Histórico Nacional. Consejos suprimidos. Libro 1.514, núm. 52, fol. 32.

10 Las ordenanzas de Valencia en AGS. CSH. Libro 202, fol. 152 y ss. La orden circular de 1771 en la Historia de la Junta General de Comercio, del propio LaRRuga, manuscrita en la Biblioteca del Ministerio de Hacienda, tomo VIII, doc. 88.

11 AGS. CSH. Libro 241, fol. 75.

12 AGS. CHS. Libro 209, fol. 17. Su papel en Valencia en MoLAS, pág. 340, según la Historia de LaRruga, 1, 1093-1098.

13 La solicitud de futura por parte de Canals fue denegada por el rey. AGS. CSH. Libro 210 , fol. 180. Las peticiones de Mansilla en Libro 241, fol. 274 y libro 244, fol. 49. 
1763 en Valencia, el mismo personaje había solicitado el nombramiento de visitador del colegio de tintoreros de aquella ciudad. En Talavera teñía las sedas en

«Quantos colores regulares se conocían y en quantos inventaban y variaban las novedades".

Benedicto pretendía, como antes Mansilla, el título de teniente visitador para ausencias y enfermedades. También proponía que en el futuro la plaza fuera provista por oposición, con acta pública y registrada ${ }^{14}$.

\section{JUAN PABLO CANALS}

Juan Pablo Canals, el sucesor de Robles, no era un maestro tintorero, sino un comerciante, dueño de una de las principales fábricas de indianas de Barcelona, que se había beneficiado regularmente de las franquicias concedidas por la Junta General de Comercio. Juan Pablo, hijo del fundador de la empresa, había viajado por el extranjero y poseía conocimientos científicos. En 1758 había ingresado en la primera promoción de la matrícula de comercio de Barcelona y en 1759 había obtenido la dignidad semi-nobiliaria de ciudadano honrado ${ }^{15}$.

El nombramiento de Canals como director de tintes se había producido a partir de otras funciones públicas relacionadas con la política industrial. En 1760 había sido enviado a Madrid como comisionado de los fabricantes de indianas catalanes para solicitar facilidades de importación de algodón hilado, y también de productos tintóreos. Una vez en la corte, se le envió a inspeccionar la cosecha de granza, a raíz de las quejas expresadas por los pueblos productores de la misma ${ }^{16}$. La misión de Canals en los pueblos de Valladolid fue tan positiva que el 28 de julio de 1763 fue nombrado "Director o inspector del cultivo y beneficio del ramo de la granza". La Junta de Comercio le encargó la formación de una compañía para el cultivo y comercio de la rubia, medida que fue criticada por el todavía

14 Ibidem, Libro 244, fol 52-53. Su actuación en Valencia en libro 249, fol. 372 . Su papel en Talavera en LARRUGA, Memorias, VIII, 176 y 304-305.

15 TORRES AMAT, Félix, Diccionario crítico de escritores catalanes, edición facsímil. Barcelona 1975 págs. 137-139. RuIz y PABLO, Ángel, Historia de la Junta de Como española. Barce Barcelona 1919, págs. 85-91. CARRERA PuJAL, Jaime, Hiśmica de Cataluña (siglos XVI-XVIII). Barlona, tomo IV, págs. 132-139. Historia política y económica celona 1947 , IV, págs. 446-449.

16 Larruga, Memorias, XXVIII, págs. 169-170. 
visitador Robles. El 2 de diciembre la granza fue eximida de los derechos de exportación y de alcabalas durante diez años ${ }^{17}$.

Canals reunió a partir de 1764 los dos cargos: el antiguo de inspector general de tintes y el nuevo de director de la granza. Su principal actividad se polarizó en este segundo ámbito. En 1768 se prohibió la exportación de la granza en bruto, aunque se permitía hacerlo con la elaborada ${ }^{18}$. En 1769 la Junta de Comercio encargó a Canals la formación de unas ordenanzas del ramo, que fueron promulgadas en octubre de $1772^{19}$.

Juan Pablo Canals es especialmente conocido por su abundante y continuada labor de publicación de obras técnicas sobre el tinte. En 1763 publicaba una traducción de la obra de Duhamel de Monceau, acompañada de un suplemento ${ }^{20}$. La Junta de Comercio de Barcelona publicó en 1766 un resumen en catalán de la obra, para facilitar su conocimiento por los labradores. El mismo procedimiento de traducción se aplicó en 1770 a la Memoria sobre la granza kermes, publicada por Canals en $1768{ }^{21}$, el mismo año en que daba una "Noticia" de los experimentos practicados por los tintoreros españoles con el tinte llamado dividivi procedente de Venezuela. En 1769, siempre por orden de la Junta de Comercio, publicó unas Memorias sobre el albayalde y sal de saturno, en relación con el establecimiento en Canillejas de la fábrica del catalán Juan Tubau, el cual actuaba "dirigido e instruido" por el propio Canals. Incluso las ordenanzas de 1772 se vieron completadas por un Suplemento de las memorias publicadas sobre la rubia ${ }^{22}$.

Años más tarde, en 1779, Canals reemprendió su labor divulgadora con unas Memorias sobre la púrpura de los antiguos restaurada en España. El mismo año, una Colección de lo perteneciente al ramo de la granza reunía la labor legislativa y científica de Canals: las reales cédulas de 1763 y 1772, la de 1776, que prorrogaba las franquicias a los cosecheros por cinco años, y las de 1760 y 1767 sobre fábricas de indianas ${ }^{23}$. En el plano científico, la Colección contenía un extracto de Duhamel, el Suple-

\footnotetext{
17 Larruga, Historia, VIII, documento 91. AGS. CSH, Libro 210, fol. $175 \mathrm{v}$.

18 Larruga, Historia, VIII, documento 93. AGS. CSH. Libro 242, fol. 83. AHN. Consejos suprimidos. Libro 1.514.

19 Larpuga, Historia, VIII, documento 313. AHN. Consejos suprimidos. Libro 1.514, fol. 339. AGS. CSH. Libro 218, fol. 265.

20 Sempere GuARINOS, Biblioteca de escritores españoles del reinado de Carlos III, edición facsímil. Madrid 1969, II, págs. 107-117.

21 La memoria sobre la granza kermes, en AHN. Consejos suprimidos, Libro 1514, fols. 211 244. Sobre el albayalde, LaRRuga, Memorias, III, pág. 176.

22 El suplemento en AHN. Consejos suprimidos. Libro 1514, fols. 254-251.

23 Las memorias sobre la púrpura en AHN. Consejos suprimidos. Libro 1.515, fols. 88 y ss.
} 
mento a las memorias de 1772 , otras memorias técnicas, por ejemplo sobre la aplicación del platino, y daba noticia de otras plantas «rubiáceas» (tanto españolas como exóticas). Según Sempere Guerinos, en $1785 \mathrm{Ca}$ nals tenía todavía una docena de memorias pendientes de publicación. Unas trataban sobre colorantes (orchilla, pastel, gualda, bonga de Filipinas) o sobre otros "simples" industriales (alumbre y caparrosa de Aragón, gomas de Indias, etc.) ${ }^{24}$.

No conocemos con detalle la labor de Canals al frente de la dirección de granza. En 1777 pasó a Valladolid para corregir «abusos». En 1785, ya al final de su vida, redactó un resumen sobre los beneficios o "utilidades" que su política había reportado al estado y a la sociedad, destacando sus largos servicios, y solicitando un sueldo proporcionado ${ }^{25}$.

Canals intentó complementar sus funciones con el establecimiento de una red de inspectores o veedores de la granza, "directores provinciales" o "visitadores de tintes". En su cédula de nombramiento se mencionaba la urgente necesidad de precaver abusos y de fomentar el comercio de la granza. Se nombraron visitadores en Madrid, Valladolid, Zaragoza, Bilbao, Barcelona y Valencia. Pero este nuevo cargo no fue de mucha duración. La política industrial de los años ochenta era partidaria de una «justa libertad, sin trabas ni embarazos». Una real cédula de 11 de diciembre de 1785 extinguía los veedores de la rubia, aunque repetía la prohibición de exportarla "en raíz o graneada» ${ }^{26}$.

Canals era miembro de diversas sociedades científicas: la Academia de Ciencias y Artes de Barcelona, la de Bellas Artes de San Fernando de Madrid, y la Económica Matritense de Amigos del País. También había ascendido en la carrera de los honores. Desde 1773 solicitaba el título de barón, con la denominación de la Granza española, bien expresiva de sus méritos industriales. En 1778 reiteró su petición, incrementada con la de una pensión a cargo de la Junta de Comercio de Barcelona, pero esta institución indicó que Canals ya cobraba 20.000 reales como director general de tintes. Por fin en 1780 se le concedió el título de barón de Vallroja ${ }^{27}$, más eufónico que el de Granza española, pero también significativo (roja era el nombre catalán de la rubia).

24 Sempere Guarinos, Op. cit

25 British Library. Mss. Egerton 507, fol. 201 y 209. Mss. Egerton 502, fol. 6

AGS. CSH. Libro 210, fol. 68.

${ }_{27}$ AHN. Consejos suprimidos, Libro 1.515, fol. 493. 


\section{TEÓRICOS DEL TINTE}

Los conceptos manifestados por Canals en sus obras eran expuestos por otros autores del momento. En su Discurso sobre el fomento de la industria popular, Campomanes se refería a la necesidad de los «buenos tintes" y realizaba la consabida alabanza del "arte de la tintorería». Pasaba revista a diversos tipos de colorantes (rubia, grana, orchilla) y proponía el establecimiento de un sistema de enseñanza técnica, desde maestros residentes en las capitales de provincia, hasta aprendices que difundieran los nuevos conocimientos en los "lugares cortos" ${ }^{28}$.

Juan Pablo Canals no era el único autor especializado en la literatura específica sobre el tinte. En 1752 el visitador de fábricas de Madrid, Benito de Novoa, había traducido un Arte de la tintura de las lanas y sus texidos ${ }^{29}$. En el decenio de los setenta la Junta General de Comercio promovió las traducciones de tratados técnicos. En esta labor destacó Miguel Jerónimo Suárez Núñez, uno de los personajes más significativos en el proceso de divulgación científica de la España ilustrada.

Suárez se había dedicado al comercio en Sevilla y Puerto de Santa María como director de una fábrica de tejidos de seda, favorecida con franquicias de la Junta de Comercio. Parece que fracasó como hombre de negocios y que se orientó hacia la administración pública. En 1766 y de nuevo en 1769-1770 viajó por España. En Talavera visitó la fábrica de sedas gestionada por la casa Ustáriz. En 1775 fue nombrado archivero de la Junta de Comercio. Fue miembro de la Sociedad Económica de Amigos del Pais de Madrid, en la sección de artes y oficios. Fue también socio de mérito de la Sociedad Vascongada y corresponsal de la Academia de Agricultura de Galicia. Su celebridad se debía a las numerosas traducciones de tratados técnicos, que llegaron a componer doce volúmenes de Memorias instructivas y curiosas, iniciadas en 1778.

En un memorial posterior Suárez afirmaba que hacía muchos años que se dedicaba al estudio de la química experimental "con la idea de perfeccionar en España el arte de la tintura». En 1769 había solicitado al fabricante de Barcelona Isidro Catalá que le enseñase los "secretos" de estampar los pintados "a la chinesca" sobre seda. Por orden de la Junta General colaboró con la de Barcelona en cuestiones relativas a la industria sedera. En 1771 tradujo el Arte de las tinturas de las sedas del francés

28 Campomanes, Discurso..., capítulo XI.

29 Escrita por Mr. Hellot, de la Academia real de las Ciencias y de la Sociedad de Londres, 472 páginas. 
Macquer, en cuya adaptación mencionaba la labor del tintorero Benedicto. En 1779 publicó una nueva traducción la del Arte de teñir las lanas, seda y algodón, o compendio de la teoría y práctica de la tintura ${ }^{30}$.

\section{LUIS FERNÁNDEZ}

Teoría y práctica se encuentran en la trayectoria del tintorero Luis Fernández, nacido en Toledo. Debió su formación técnica a su propio padre, y tras la muerte de éste a Francisco Sedeño. Aunque alabó a sus maestros, Fernández no dudó en calificar su formación empírica de "confuso estilo». Desde joven se dedicó a investigar y experimentar, hasta que, bajo la aprobación de la Junta General de Comercio, se le nombró maestro tintorero, o más enfáticamente director de tinte, de la fábrica de seda que los Cinco Gremios Mayores de Madrid mantenían en Valencia. El propio Fernández describía su tinte como "uno de los objetos de curiosidad que contiene Valencia". Aunque el gremio de tintoreros presentó una protesta contra él en 1773, el toledano alabó la preparación de algunos valencianos: Pascual Perea y Bruno Llovet. Tuvo buenas relaciones con el experto fabricante de tejidos de seda Joaquín Manuel Fos, y colaboró con la Junta particular de comercio de Valencia. La Junta General le encargó la formación de unas "ordenanzas generales, gubernativas e instructivas del arte de tintoreros». Fruto de esta sugerencia fue el Tratado instructivo y práctico del arte de la tintura, publicado en Madrid en $1778^{31}$.

El Tratado estaba dedicado a los directores de la compañía de los Cinco Gremios, que habían financiado la edición. La General de Comercio se encargó de enviar ejemplares a las juntas particulares, por ejemplo, a la de Barcelona. La obra respondía a la intencionalidad ilustrada de dar "principios y reglas fijas" a una técnica, que hasta entonces se había ejercido «de mera tradición». El subtítulo especificaba que se daban «reglas experimentadas y metódicas". El Tratado se dividía en tres partes, según el tipo de materia textil: 1) sedas, 2) lanas, 3) hilos de todas clases y esparto en rama. También se manifestaban las condiciones que debía reunir un buen tintorero para ejercer su oficio con "legalidad y primor", dos conceptos bien expresivos del modelo que se intentaba promover.

El año 1778 marcó el punto culminante de la carrera de Luis Fernández. La Junta de Comercio de Valencia sugirió que se le nombrara inspector

30 Garzón Pareja, M. La industria sedera en España. Granada 1972, págs. 201-294. Sem. Pere Guarinos, VI, 231. AHN. Estado. Leg. 2.923, núm. 487.

31 MOLAs Pere, Op. cit., págs. 339-341. 
general de tintes del reino. El fiscal de la Junta de Comercio propuso que se le nombrara director provincial de tintes, bajo la dirección de Juan Pablo Canals. Su ámbito de actuación no se limitaría al reino de Valencia, sino que tendría obligación de trasladarse a Murcia o Granada (dos ciudades sederas), cuando la Junta se lo indicase. El fiscal proponía que se asignase a Fernández una pensión anual de 12.000 reales. La definitiva real orden de 7 de marzo de 1779, que le nombraba visitador de tintes del reino de Valencia, rebajaba la pensión a 8.000 reales, que debian pagarse de los fondos del consulado de comercio ${ }^{32}$.

Fernández realizó efectivamente en 1779 y 1781 la inspección de los tintes del reino de Valencia, pero ya en 1783 solicitaba que se nombrase un teniente visitador, escogido entre los tintoreros valencianos. Al mismo tiempo ampliaba su ámbito de actuación, tanto en lo geográfico como en lo técnico. En 1782 colaboró con la Sociedad Económica de Amigos del País de Segovia. La institución homónima de Valencia le premió tres memorias. Dos de ellas versaban sobre la industria del tinte. La tercera se refería a la fabricación de medias de seda, otra especialidad en la que destacó Fernández. En 1789 se encontraba en su ciudad natal, interesado en la cosecha de seda. Tantas ausencias motivaron que en 1792 la dirección de los Cinco Gremios le retirara el pago de su salario. Carlos IV le concedió el título de fabricante de la casa real. Establecido en Madrid, perteneció a la clase de artes de la Sociedad Económica, pero desde 1806 dejó de cobrar la pensión del Consulado de Valencia ${ }^{33}$.

\section{TINTOREROS CATALANES Y VALENCIANOS}

Un paralelo en tono menor de la carrera de Luis Fernández en Valencia fue el tintorero de seda y telas de Barcelona, José Vinyes. En 1775 solicitó el título de tintorero del rey, y en 1779 escribió a los ministros de hacienda y estado, proponiendo un proyecto para mejorar los tintes. Su propio gremio exponía los "inventos" y nuevos colorantes y colores puestos en uso por Vinyes. En 1780 se le nombró veedor del ramo de la granza. Más adelante manifestó que el había sido el consejero técnico de Canals en la Colección publicada en 1779. Solicitó a la Junta General de Comercio la concesión de algunas gracias, y cansado de esperar se decidía a mar-

32 AGS. CSH. Leg. 370, núm. 42. Libro 242, fol. 108.

33 Gaceta de Madrid, 13 de diciembre 1782. Larruga, Memorias, XIII, págs. 254-255, AleI. xANDRE, Francisca, Catálogo del Archivo de la Real Sociedad Económica de Amigos del País. Valencia 1978 
char al extranjero. Alegaba que tras haber leído el Tratado de Fernández había mejorado su método, consiguiendo colores más vivos y delicados a menos coste, por lo que pedía el título de visitador de tintes en Cataluña. En 1783 se le concedió una pensión y se le llamó a Madrid. Al año siguiente se le pidió que redactara el consabido tratado técnico. Este fue el Quadern, con instrucciones prácticas sobre el arte del tinte, "comprobadas ab la experiencia y observació propia». Esta obrita, que no llegó a imprimirse, se dividía en tres partes, según el tejido a teñir fuera seda, hilo o lana. Utilizaba como colorantes el palo de Brasil o Campeche, la granza, la orchilla y la bonga ${ }^{34}$

A Vinyes se le había indicado que escribiera un libro como el redactado por el fabricante de tejidos de seda, Isidro Catalá y Vives. Este personaje habia recibido desde 1749 franquicias de la Junta General de Comercio para la fabricación de tejidos de seda pintados a la chinesca ${ }^{35}$. Era también socio de una fábrica de indianas. En 1768 se concedió a su establecimiento el título de fábrica real. La Junta General pidió a la de Barcelona que tanteara el premio que pediría Catalá para "comunicar el secreto de dar los colores". En 1770 se le concedió una pensión anual de 2.000 pesos, a cambio de la obligación de formar, en grupos de dos, a los aprendices que le propusiera la Junta. También debía escribir un tratado técnico "con claridad y distinción». Además fue dotado de poderes de inspección, con el título de veedor de las fábricas de tejidos de seda pintados a la chinesca del Principado ${ }^{36}$.

Los términos del acuerdo no fueron totalmente satisfactorios. Aunque se habían tomado medidas para evitar que los discípulos de Catalá le hicieran una competencia desleal, no pudo impedir que se produjera esta situación. Además parece que el flamante veedor utilizó sus poderes de inspección para dificultar la producción de un rival: el mercader de lienzos Tomás Llimona. Como algo semejante sucedió en Valencia con Joaquín Manuel Fos con la fabricación de tejidos de seda, estos hechos confirman la idea de Mr. Roland, inspector francés de manufacturas, de que los reglamentos de tinte se convertían en instrumento de venganzas personales ${ }^{37}$. Catalá murió en 1788 . Su hijo y otro fabricante aspiraban a sucederle, pero el cargo no se cubrió.

${ }_{34}$ AGS. CSH. Libro 203, fol. 247. Libro 210, fols. 151 y 249. Archivo de la Corona de Aragón.

896 fol. 101. Caraera Pujal, Historia... Cataluña, $N$, págs. 227-228.

35 Carrera Pujal, J., Historia... Cataluña, IV, págs. 119, 128, 211 y ss. AGS. CSH. Libro

213 , fol. 92 , págs. 233 y ss. Libro 242 , fols. 83-85.

36 Carrera Pujal, J., IV, 211. Ruiz y Pablo, 76

${ }^{37}$ La opinión de Roland en Encyclopédie Méthodique, II, Discurso preliminar. 
Menor entidad tiene la figura de Luis Cantarell, miembro de una dinastía de tintoreros. Su abuelo Luis había sido nombrado en 1731 tintorero de la ciudad de Barcelona, cargo que logró ceder en 1738 a su hijo Jacinto ${ }^{38}$. El hijo de éste, Jacinto Cantarell y Rovira, intervino en la industria de indianas, junto a su cuñado Ramón Pujol, en la compañía «Pujol y Cantarell». Otro cuñado de Pujol era precisamente Isidro Catalá.

Cantarell financió la fabricación de los tejidos llamados serafinas por parte del tejedor Francisco Curras, que le enseñó la técnica. Curras se estableció en Madrid en 1769 y solicitó una subvención a la Junta de Comercio para mantener una fábrica que al mismo tiempo fuera un centro de enseñanza técnica. Años más tarde, en 1786, Luis Cantarell se presentaba como fabricante de lienzos pintados y único fabricante de serafinas, pero la administración le clasificó únicamente como tintorero o estampador de pintados ${ }^{39}$.

En Valencia continuó en los años ochenta el interés por la reforma del tinte. Luis Pérez Sancho estableció una escuela en la Sociedad Económica de Amigos del País en 1788. Al año siguiente se refería a su «invención» y al método de etintar o dar los colores con la mayor perfección, hermosura y fineza". Publicó en las Memorias de la Real Sociedad Patriótica de Sevilla unas Relexiones sobre el arte de la tintura, en las que comentaba una vez más el carácter rutinario de la formación técnica artesanal: «mera práctica... sin otros principios que la tradición vulgar» ${ }^{40}$.

Otro maestro, Miguel Jerónimo Fuentes, se trasladó de Valencia a Madrid para enseñar la preparación de medias de color blanco plata al maestro del Hospicio de Madrid. A cambio recibió el derecho a colocar las armas reales en su casa tinte ${ }^{41}$.

Los tintoreros seguian exponiendo a la administración los «secretos" de su oficio, para obtener protección y recompensa, como hacía en 1784 el catalán José Oriol, que se definía como fabricante de tintes ${ }^{42}$. En 1802 se concedió escudo de armas reales a un fabricante de Olot, y al coruñés Juan Antonio Rodríguez de Arjún, cuyo «laboratorio» era considerado por el intendente como el «único tan general de aquella clase» en Galicia,

\footnotetext{
ACA. Audiencia, volumen 215, fols. 76-77.

39 Carrera Pujal, J., Historia... Cataluña, IV, 90-91 y 223. Larruga, Memorias, II, 286-289. AGS. Dirección general de rentas, leg. 434.

40 Carrera Pujal, Historia economía española, IV. Barcelona 1945, págs. 187-188. Aleixan-

4 Archivo del Reino de Valencia. Real Acuerdo. Volumen 84, fol. 823

42 AGS. CSH. Leg. 262, núm. 26.
} DRE, documento 373. 
donde sólo había, según el propio aspirante, «algunos pocos teñidores de pocos conocimientos y para pocos colores" ${ }^{43}$.

Los tintoreros eran conscientes del componente científico de su oficio. En 1801 los de la población riojana de Ezcaray se titulaban «Colegio de Tintología" ${ }^{44}$. En 1816 los tintoreros de seda y telas de Barcelona reivindicaron el título de colegio, una denominación que en la tradición artesana de Barcelona se reservaba para las «artes" consideradas liberales y no mecánicas. Los tintoreros de seda alegaban que su profesión necesitaba más el ingenio que otras corporaciones, y tenía más analogía con las ciencias.

Aunque la administración había ido abandonando la práctica de los inspectores de manufacturas, todavía en febrero de 1808 un tintorero de Vic, que había sido maestro de tintes en la fábrica de Guadalajara, solicitaba, además del título de real para su empresa, el nombramiento de visitador general de tintes, «en los mismos términos que to fue don Juan Pablo Canals» ${ }^{45}$.

43 Ibidem, Leg. 386, núm. 74.

44 Ibidem, Leg. 278, núm. 2.

45 Biblioteca de Catalunya. Junta de Comercio. Leg. 13. 